\title{
Effects of diltiazem and propafenone on the inactivation and recovery kinetics of fKv1.4 channel currents expressed in Xenopus oocytes
}

\author{
Dong ZHANG ${ }^{1,2, *}$, Shi-min WANG ${ }^{1}$, Hui CHEN ${ }^{2}$, Xue-jun JIANG ${ }^{1}$, Sheng-ping CHAO ${ }^{2}$ \\ ${ }^{1}$ Department of Cardiology, Renmin Hospital, Wuhan University, Wuhan 430073, China; ${ }^{2}$ Department of Cardiology, Zhongnan Hospi- \\ tal, Wuhan University, Wuhan 430071, China
}

\begin{abstract}
Aim: To investigate the effects of diltiazem, an L-type calcium channel blocker, and propafenone, a sodium channel blocker, on the inactivation and recovery kinetics of fKv1.4, a potassium channel that generates the cardiac transient outward potassium current. Methods: The cRNA for fKv1.4AN, an N-terminal deleted mutant of the ferret Kv1.4 potassium channel, was injected into Xenopus oocytes to express the fKv1.4 $\mathrm{N}$ channel in these cells. Currents were recorded using a two electrode voltage clamp technique. Results: Diltiazem (10 to $1000 \mu \mathrm{mol} / \mathrm{L}$ ) inhibited the fKv1.4 $\Delta \mathrm{N}$ channel in a frequency-dependent, voltage-dependent, and concentration-dependent manner, suggesting an open channel block. The $\mathrm{IC}_{50}$ was $241.04 \pm 23.06 \mu \mathrm{mol} / \mathrm{L}$ for the fKv1.4 $\Delta \mathrm{N}$ channel (at +50 $\mathrm{mV})$, and propafenone $(10$ to $500 \mu \mathrm{mol} / \mathrm{L})$ showed a similar effect $\left(\mathrm{IC}_{50}=103.68 \pm 10.13 \mu \mathrm{mol} / \mathrm{L}\right)$. After application of diltiazem and propafenone, fKv1.4 $\Delta \mathrm{N}$ inactivation was bi-exponential, with a faster drug-induced inactivation and a slower C-type inactivation. Diltiazem increased the $\mathrm{C}$-type inactivation rate and slowed recovery in fKv1.4 $\Delta \mathrm{N}$ channels. However, propafenone had no effect on either the slow inactivation time constant or the recovery.

Conclusion: Diltiazem and propafenone accelerate the inactivation of the Kv1.4 $\Delta \mathrm{N}$ channel by binding to the open state of the channel. Unlike propafenone, diltiazem slows the recovery of the $\mathrm{Kv} 1.4 \Delta \mathrm{N}$ channel.
\end{abstract}

Keywords: inactivation; recovery; Kv1.4; potassium channel; diltiazem; propafenone; two electrode voltage clamp technique

Acta Pharmacologica Sinica (2011) 32: 465-477; doi: 10.1038/aps.2010.234

\section{Introduction}

Transient outward potassium currents $\left(I_{\mathrm{to}}\right)$ contribute to the early repolarization phase of the cardiac action potential ${ }^{[1,2]}$. Two types of $I_{\text {to }}$ are known: $I_{\text {to }}$ (fast), which shows fast recovery kinetics, and $I_{\text {to }}$ (slow), which shows slow recovery kinetics that are related to accumulated inactivations ${ }^{[3]}$. As the major component of $I_{\text {to }}$ (slow), the Kv1.4 channel plays an important role in the repolarization of cardiac myocytes. Kv1.4 channels were inactivated by two well-established processes: Nand C-type inactivation. N-type inactivation results from the occlusion of the intracellular side of the pore by a "ball and chain" mechanism formed by the $\mathrm{NH}_{2}$ terminus of the channel molecule $e^{[4-9]}$, while C-type inactivation involves conformational changes on the extracellular side of the pore ${ }^{[10]}$. These two mechanism are coupled ${ }^{[5]}$; C-type inactivation is more rapid in the presence of $\mathrm{N}$-type inactivation ${ }^{[11]}$ and can be affected by open channel blockers. Recovery from inactivation

\footnotetext{
* To whom correspondence should be addressed. E-mail vividcurio@yahoo.com.cn

Received 2010-06-28 Accepted 2010-12-18
}

is controlled by the slower C-type mechanism ${ }^{[11]}$, which makes it physiologically important.

The L-type calcium channel blocker diltiazem and the sodium channel blocker propafenone are widely used in clinics for the treatment of cardiovascular diseases of hypertension, cardiac angina (for diltiazem) and arrhythmias ${ }^{[12-14]}$. The therapeutic effects are generally believed to be related to the L-type calcium channel (for diltiazem) and the sodium channel (for propafenone). Recent studies demonstrated that diltiazem inhibited the hKv1.5 channel, which conducts ultra rapid delayed rectifier currents $\left(I_{\mathrm{kur}}\right)$, and $I_{\mathrm{to}}$, encoded by Kv4.3 by binding to the open and the inactivated states of the channels ${ }^{[15-17]}$. There is evidence that diltiazem decreases Kv1.4 channel currents expressed in the oocytes of Xenopus laevis ${ }^{[16]}$, and propafenone was shown to be an open channel antagonist of Kv1.4 channel currents ${ }^{[18]}$, but their detailed characteristics have not been studied.

The present study, in which we used an N-terminal deletion construct of $\mathrm{Kv} 1.4(\mathrm{Kv} 1.4 \Delta \mathrm{N})$ that lacks rapid N-type inactivation but exhibits robust C-type inactivation ${ }^{[19]}$, was therefore designed for the following: (1) to study the properties of 
diltiazem blockade of the fKv1.4 $\Delta \mathrm{N}$ channel; (2) to study the effect of diltiazem on Kv1.4 channel C-type inactivation and recovery, and (3) to compare the electrophysiological effects of diltiazem on $\mathrm{fKv} 1.4 \Delta \mathrm{N}$ with those of propafenone.

\section{Materials and methods Molecular biology}

The constructs and sequences of the cDNA fKv1.4 $\Delta \mathrm{N}$ used in this study have been previously described ${ }^{[19-21]}$ and were a gift from professor Randall L RASMUSSON (University at Buffalo, SUNY). The construction of $\mathrm{fKv} 1.4 \Delta \mathrm{N}$ was performed by removal of 2-146 amino acid residues from the N-terminal domain of Kv1.4, which results in the loss of the fast component of inactivation but leaves the C-type inactivation pathway intact ${ }^{[19-21]}$. Transcribed fKv1.4 $\mathrm{N}$ cRNA was prepared in vitro using an mMessage mMachine kit (T3 kit, Ambion, USA).

\section{Isolation of oocytes and incubation}

Oocytes were collected from mature female Xenopus laevis frogs (Chinese Academy of Science, Beijing, China). Frogs were anesthetized (immersion in $1.5 \mathrm{~g} / \mathrm{L}$ tricaine) for $30 \mathrm{~min}$, followed by surgical removal of the ovarian lobes through a lateral incision in the lower abdomen. The incision was then sutured, and the frog was allowed to recover in a container with a small amount of water. When the frogs did not produce a high quality of oocytes, they were humanely killed via a high dose of tricaine. All procedures were approved by the Institutional Animal Care and Use Committee of the Wuhan University of China.

The follicular layer was removed enzymatically by placing the ovarian lobes in a collagenase-containing, $\mathrm{Ca}^{2+}$-free $\mathrm{OR}_{2}$ solution (mmol/L: $82.5 \mathrm{NaCl}, 2 \mathrm{KCl}, 1 \mathrm{MgCl}_{2}$ and 5 Hepes, $\mathrm{pH}$ 7.4, with $1-1.5 \mathrm{mg} / \mathrm{mL}$ collagenase (Type I, Sigma, USA). The oocytes were gently shaken for about $1 \mathrm{~h}$ and washed several times with $\mathrm{Ca}^{2+}$-free $\mathrm{OR}_{2}$ solution as previously described ${ }^{[13]}$. Finally, defolliculated (stage IV) oocytes were selected and placed in ND96 solution (mmol/L): $96 \mathrm{NaCl}, 2 \mathrm{KCl}, 1 \mathrm{MgCl}_{2}$, $1.8 \mathrm{CaCl}_{2}$ and 5 Hepes, $\mathrm{pH}$ 7.4. Each oocyte was injected with about $25-50 \mathrm{~nL}$ of fKv1.4 $\Delta \mathrm{N}$ cRNA using a microinjector (WPI, Sarasota) and incubated in an $18{ }^{\circ} \mathrm{C}$ environment in ND96 solution with $100 \mathrm{IU} / \mathrm{mL}$ penicillin for over $16 \mathrm{~h}$.

\section{Electrophysiology}

The experiment was carried out using a two electrode voltage clamp technique. Oocytes were clamped using a preamplifier CA-1B (DAGAN, USA), and the current signals were filtered at $2.5 \mathrm{kHz}$. Microelectrodes were fabricated from 1.5 $\mathrm{mm}$ o.d. borosilicate glass tubing using a two-stage puller (NARISHIGE, Japan) to produce electrodes with resistances of $0.5-1.0 \mathrm{M} \Omega$ when filled with $3 \mathrm{mmol} / \mathrm{L} \mathrm{KCl}$. Currents were recorded at room temperature $\left(20-24^{\circ} \mathrm{C}\right)$. Recordings were made in $2 \mathrm{~mol} / \mathrm{L}\left[\mathrm{K}^{+}\right]_{\mathrm{o}}$. Diltiazem and propafenone were separately dissolved in distilled water with a stock solution of $100 \mathrm{mmol} / \mathrm{L}$. During recording, oocytes were continuously perfused with a control (ND96) or drug-containing ND96 solution. Whenever drugs were used, $10 \mathrm{~min}$ of perfusion time was used to allow equilibration of the drug with the oocytes. After this wash-on period, a series of $500 \mathrm{~ms}$ depolarizing pulses (from $-90 \mathrm{mV}$ to $+50 \mathrm{mV}$ at a frequency of $1 \mathrm{~Hz}$ for $1 \mathrm{~min}$ ) was employed to ensure a steady-state block before beginning the experimental protocols ${ }^{[20]}$.

\section{Data analysis}

Data were recorded with a personal computer installed with pCLAMP 9.0 (Axon, USA) and analyzed using Clampfit 9.0 (Axon, USA) and Microsoft Excel software (Microsoft, USA). Unless otherwise stated, raw data traces were not leakage or capacitance subtracted. Data are shown as means \pm SEM. Significant differences were determined using Student's paired $t$-tests.

\section{Results}

Effects of diltiazem on fKv1. $4 \Delta \mathrm{N}$ currents

Voltage-, concentration-, and frequency-dependent blockade of diltiazem on fKv1.4AN currents

Figure 1A shows representative fKv1.4 $\Delta \mathrm{N}$ current traces recorded by applying $5 \mathrm{~s}$ pulses from $-100 \mathrm{mV}$ to $+50 \mathrm{mV}$ in 10 $\mathrm{mV}$ increments in the control, in the presence of $250 \mu \mathrm{mol} / \mathrm{L}$ diltiazem, and after the drug washout. The fKv1.4 $\Delta \mathrm{N}$ currents were substantially inhibited by the application of $250 \mu \mathrm{mol} / \mathrm{L}$ diltiazem and the effect recovered after washout of the drug for $10 \mathrm{~min}$.

Peak-voltage relationships from the control, $250 \mu \mathrm{mol} / \mathrm{L}$ diltiazem-treated and drug washout oocyte groups were plotted against clamp potential in Figure 1B. In this figure, the $I_{\mathrm{DIL}} / I_{\mathrm{CON}}$ ratio was plotted as a function of the membrane potential. Diltiazem decreased the peak currents at transmembrane potentials positive to the activation threshold $(-30 \mathrm{mV})$. The blockade increased steeply in the voltage range coinciding with that of channel activation (between $-40 \mathrm{mV}$ and $-20 \mathrm{mV}$ ) and remained constant at voltages above this range. The peak current was blocked by $52.21 \% \pm 4.63 \%$ when the cell membrane was depolarized to $+50 \mathrm{mV}$ in $250 \mu \mathrm{mol} / \mathrm{L}$ diltiazem, and the effect was reversed by $95 \%$ after the drug washout. There was a voltage dependence to the action of diltiazem, a phenomenon typical of open channel block.

Figure $1 \mathrm{C}$ shows the concentration dependence of fKv1.4AN current inhibition by diltiazem. Inhibition of the currents in a concentration-dependent manner was measured at the end of a $300 \mathrm{~ms}$ pulse of $+50 \mathrm{mV}$. A nonlinear least-squares fit of the Hill equation to the individual data points yielded an apparent dissociation constant, $K_{\mathrm{D}}$, for an open channel blockade of $241.04 \pm 23.06 \mu \mathrm{mol} / \mathrm{L}(n=5)$.

To evaluate the longer-term effects of exposing the fKv1.4 $4 \mathrm{~N}$ channel to diltiazem, we applied a series of $500 \mathrm{~ms}$ depolarizing pulses from $-90 \mathrm{mV}$ to $+50 \mathrm{mV}$ with a frequency of $1 \mathrm{~Hz}$ for a period of $1 \mathrm{~min}$. Figure 2 shows the peak currents elicited by this protocol, before and after exposure to 250 $\mu \mathrm{mol} / \mathrm{L}$ diltiazem, normalized to the first peak current under control conditions. With increasing pulse numbers, currents in both the control and the diltiazem-treated groups decreased. The first pulse of the pulse train in the presence of $250 \mu \mathrm{mol} / \mathrm{L}$ 

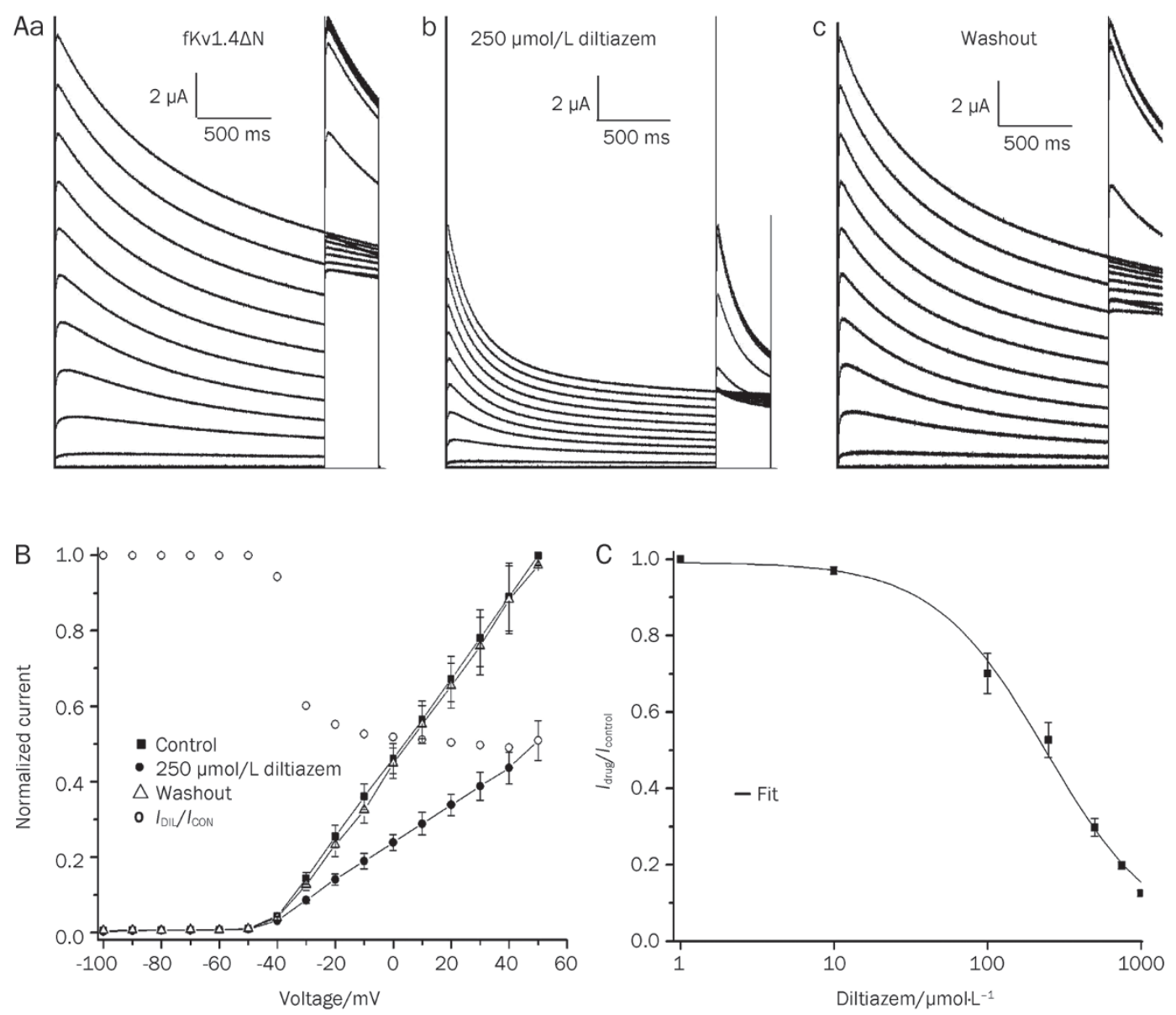

Figure 1. Voltage- and concentration-dependent blockade of fKv1.4AN currents by diltiazem. (A) Channels were expressed in Xenopus oocytes and recorded with the two electrode voltage clamp technique. Currents were obtained by applying $5 \mathrm{~s}$ pulses to potentials $\left(P_{1}\right)$ ranging from $-100 \mathrm{mV}$ to +50 $\mathrm{mV}$ and were followed by the tail currents obtained upon repolarization to $+50 \mathrm{mV}\left(\mathrm{P}_{2}\right)$ under control conditions (a), then in the presence of $250 \mu \mathrm{mol} / \mathrm{L}$ diltiazem (b), and finally after $10 \mathrm{~min}$ of washout (c). (B) Current-voltage relationships of fKv1.4 $\Delta \mathrm{N}$ channels under control conditions, in the presence of $250 \mu \mathrm{mol} / \mathrm{L}$ diltiazem, and after the drug washout for $10 \mathrm{~min}$. Currents were normalized to the peak current at $+50 \mathrm{mV}$ under control conditions. The $I_{\mathrm{DI}} / I_{\text {CoN }}$ ratio was plotted as a function of the membrane potential. Data are shown as means $\pm S E M$. ( $n=5$ ). (C) Dose-response relationships for diltiazem inhibition of fKv1.4AN channels at $2 \mathrm{mmol} / \mathrm{L}\left[\mathrm{K}^{+}\right]_{0}$. Data were obtained upon repolarization to $-90 \mathrm{mV}$ after $1 \mathrm{~s} \mathrm{pulses} \mathrm{to}+50 \mathrm{mV}$, holding potential $-90 \mathrm{mV}$. All values shown were normalized to the peak current in the absence of drug in $2 \mathrm{mmol} / \mathrm{L}\left[\mathrm{K}^{+}\right]_{0}$. Continuous line was derived by fitting the data to the Hill equation: $f=K_{D} /\left(K_{D}+D\right)$, where $f$ is fractional current, $K_{D}$ is the apparent dissociation constant, and $D$ is the diltiazem concentration. Symbols and error bar are means \pm SEM. fKv1.4AN current was reduced to $50 \%$ by $241.04 \pm 23.06 \mu \mathrm{mol} / \mathrm{L}$.

A

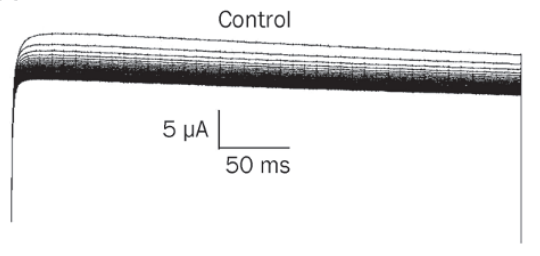

B

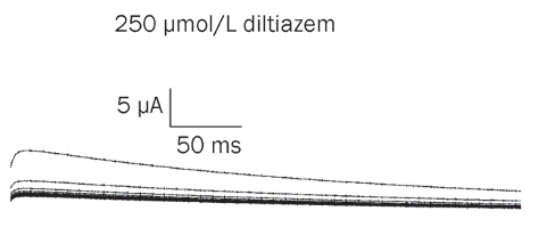

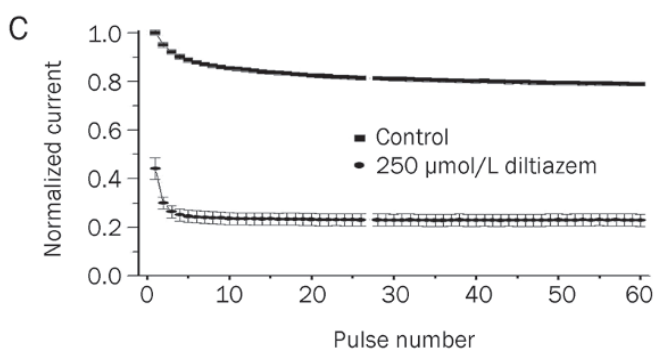

Figure 2. Frequency-dependent block of fKv1. $4 \Delta \mathrm{N}$ channels by diltiazem. Currents were elicited by applying a series of depolarising pulses from - 90 $\mathrm{mV}$ to $+50 \mathrm{mV}$ with a frequency of $1 \mathrm{~Hz}$ in the absence (A) and in the presence of $250 \mu \mathrm{mol} / \mathrm{L}$ diltiazem (B). The peak currents shown in Panel A and B were normalized to the maximum control value without drug and plotted in Panel $\mathrm{C}$. As pulse number increased, currents in both control and diltiazemtreated groups decreased. In control cells, there was a use-dependent reduction in the magnitude of the peak current. When cells were exposed to $250 \mu \mathrm{mol} / \mathrm{L}$ diltiazem for $10 \mathrm{~min}$ before stimulation, there was a reduction in the magnitude of the first peak current compared to the control value and then a use-dependent component. The use-dependent reduction in current with diltiazem was much greater than that seen in control. 
diltiazem showed a decrease relative to the pre-drug control, and the magnitude of this reduction in current was similar to that seen under steady-state conditions when a sufficiently long recovery time was allowed between test pulses. In both the control and the $250 \mu \mathrm{mol} / \mathrm{L}$ diltiazem protocols, there was a use-dependent decrease in the peak current when stimulated at $1 \mathrm{~Hz}$, but this use-dependent decrease was considerably greater in $250 \mu \mathrm{mol} / \mathrm{L}$ diltiazem than under the control conditions. In control oocytes, the peak current decayed monoexponentially from $100 \%$ to $78.86 \%$. In contrast, in $250 \mu \mathrm{mol} / \mathrm{L}$ diltiazem the current decayed from $44.14 \%$ to $23.07 \%$.

\section{Effect of diltiazem on the steady inactivation of peak Kv1.4LN currents}

Figure 3A shows the time-dependent progression of the channel from the rapid open block conformation into a diltiazeminduced block during a single depolarizing step from $-90 \mathrm{mV}$ to $+50 \mathrm{mV}$. For comparison, all current traces were normal- ized to the peak values under control conditions. In control conditions, the rate of inactivation of $f K v 1.4 \Delta \mathrm{N}$ was monoexponential with a time constant of $2.32 \pm 0.41 \mathrm{~s}(n=6)$. In the presence of 10 to $1000 \mu \mathrm{mol} / \mathrm{L}$ diltiazem, inactivation became bi-exponential, with a dominant fast exponential.

Figure $3 \mathrm{~B}(\mathrm{a})$ shows steady-state inactivation as a function of holding potential for the $\mathrm{fKv} 1.4 \Delta \mathrm{N}$ channel both before and after exposure to diltiazem. The relationships were determined from the two pulse protocol by calculating the ratio of the magnitude of the peak current in $\mathrm{P}_{2}$ to the maximum of the $P_{2}$ obtained when $P_{1}$ was $-100 \mathrm{mV}$. In this panel, diltiazem can be seen to shift the voltage dependence of inactivation to the left. In order to correct the visual error caused by different minimum values, the steady-state inactivation relationships were renormalized [Figure 3B(b)], thus preferably displaying the drift of the steady inactivation curve before and after diltiazem treatment. Figure $3 \mathrm{~B}(\mathrm{~b})$ also shows this shift to the left. The half-inactivation $\left(V_{1 / 2}\right)$ and slope factor $(k)$ values from
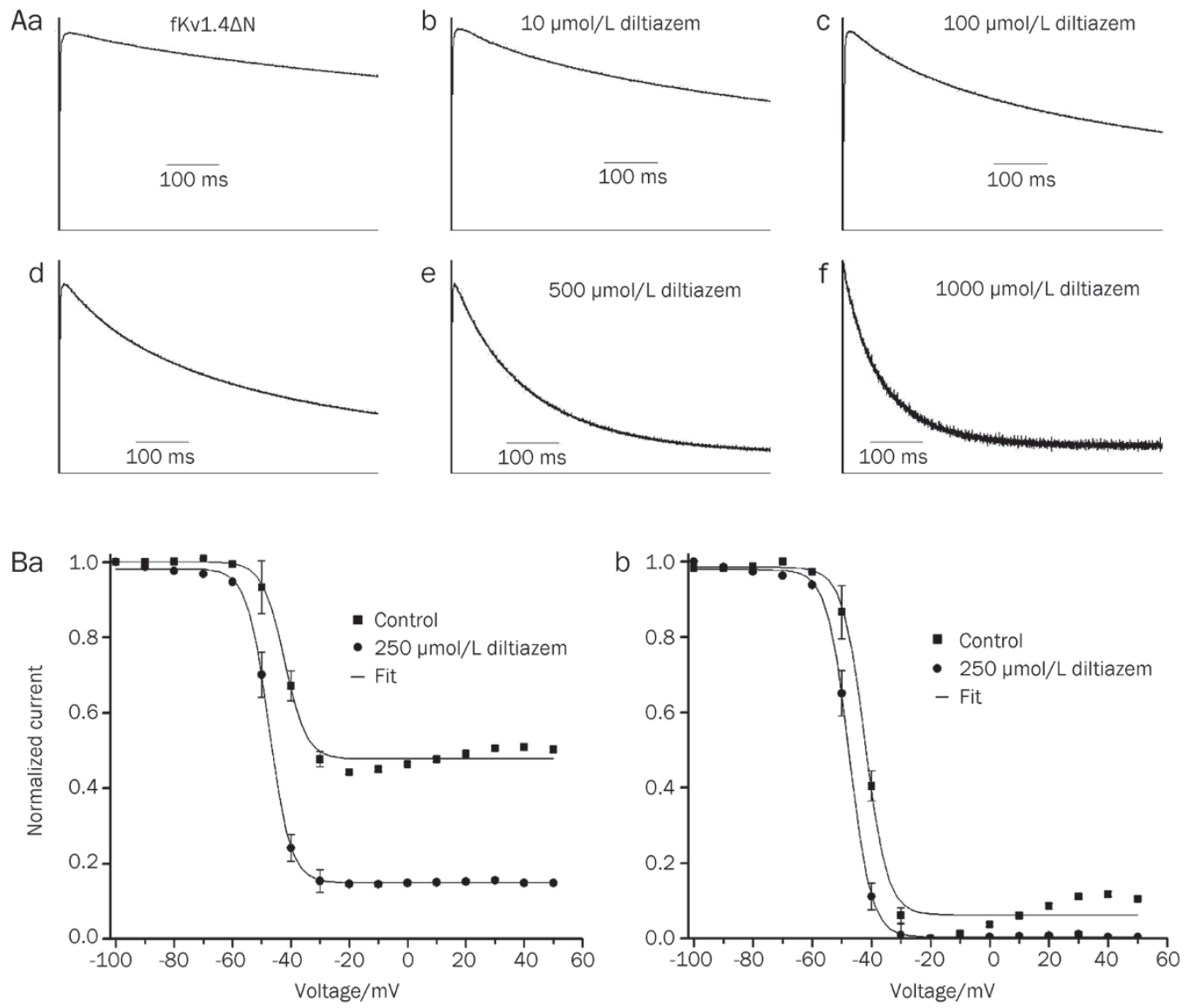

Figure 3. Effect of diltiazem on the steady inactivation of peak Kv1.4 $\Delta \mathrm{N}$ currents. (A) The time-dependent progression of channel currents. Currents were elicited by applying $1 \mathrm{~s}$ pulses from $-90 \mathrm{mV}$ to $+50 \mathrm{mV}$ in the absence and presence of increasing concentrations of diltiazem. For comparison, all current traces were normalized to the peak values under control conditions. The smooth continuous line superimposed on each trace is the best fit of an exponential function, used to determine the inactivation time constant (s). The control trace was best fitted by a mono-exponential function (Chebyshev method) (a), whereas in the presence of $10 \mu \mathrm{mol} / \mathrm{L}-1000 \mu \mathrm{mol} / \mathrm{L}$ diltiazem, inactivation was best fitted by a bi-exponential function (LevenbergMarquardt) (b-f). (B) Steady-state inactivation relationships (a). The steady-state inactivation for each $P_{1}$ voltage was calculated as the magnitude of the peak current in $P_{2}$ compared with that from the maximum of the $P_{2}$ obtained when $P_{1}$ was $-100 \mathrm{mV}$. Average data are shown as mean $\pm S E M$.

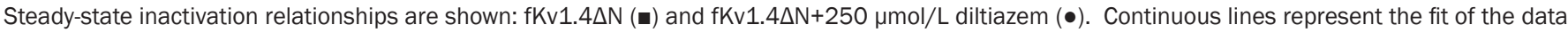
to a Boltzmann equation: $\left.f=1 /\left\{1+\exp ^{*}\left[\left(V-V_{1 / 2}\right) / k\right)\right]\right\}$. Steady-state inactivation relationships were re-normalized (b). 
$\mathrm{fKv} 1.4 \Delta \mathrm{N}$ without diltiazem and $\mathrm{fKv} 1.4 \Delta \mathrm{N}$ with $250 \mu \mathrm{mol} / \mathrm{L}$ diltiazem presented in Figure 4A ( $\mathrm{a}$ and b) are similar. No statistical difference was observed between the control and diltiazem conditions. The $K$ was $4.58 \pm 0.75(n=6)$ in the control and $5.06 \pm 0.78(n=6)$ in the diltiazem treated group, and the $V_{1 / 2}$ was $-38.38 \pm 0.81 \mathrm{mV}$ in the control and $-39.23 \pm 0.85 \mathrm{mV}(n=6)$ in the diltiazem treated group.

Inactivation of $\mathrm{fKv} 1.4 \Delta \mathrm{N}$ is best fitted by a single exponential function (Figure 4B), with an inactivation time constant ( $\left.\tau_{\text {inactivation}}\right)$ that averaged $2.32 \pm 0.41 \mathrm{~s}(n=6)$ at $+50 \mathrm{mV}$. In the presence of diltiazem, the inactivation of $\mathrm{fKv} 1.4 \Delta \mathrm{N}$ is best fitted with a bi-exponential function, with $\tau_{\text {fast }}=0.41 \pm 0.04 \mathrm{~s}$ and $\tau_{\text {slow }}=1.78 \pm 0.29 \mathrm{~s}$ at $+50 \mathrm{mV}(n=6)$ [Figure $4 \mathrm{~A}(\mathrm{c})$ ], where $\tau_{\text {fast }}$ represents the time constant of inactivation induced by the drug and $\tau_{\text {slow }}$ represents the time constant of C-type inactivation. We found that C-type inactivation was obviously accelerated by $250 \mu \mathrm{mol} / \mathrm{L}$ diltiazem at $+50 \mathrm{mV}$. Over the range $0 \mathrm{mV}$ to $+50 \mathrm{mV}$, there is no voltage sensitivity to $\tau_{\text {inactivation }}(P>0.05$, $n=6)$. In the presence of diltiazem, $\tau_{\text {fast }}$ is voltage independent, whereas $\tau_{\text {slow }}$ is voltage dependent. The time constant of C-type inactivation changes was independent of voltage, indicating that C-type inactivation of the $\mathrm{fKv} 1.4 \Delta \mathrm{N}$ channel is at least partly independent on activation. Thus, above $0 \mathrm{mV}$, C-type inactivation has nothing to do with the degree of depolarization of membrane voltage; however, C-type inactivation becomes correlated to activation in the presence of diltiazem.

Figure $4 \mathrm{C}$ shows the plot of the $1 / \tau_{\text {block }}$ as a function of the diltiazem concentration for data obtained at concentrations between $10 \mu \mathrm{mol} / \mathrm{L}$ and $1000 \mu \mathrm{mol} / \mathrm{L}$. The straight line is the least-squares fit to the equation $\left(1 / \tau_{\text {block }}=k_{+1}[d]+k_{-1}\right)$. Slope and intercept with the ordinate axis for the fitted relation yielded a $k_{+1}$ and $k_{-1}$ of $(0.01 \pm 0.002) \times 10^{6}(\mathrm{~mol} / \mathrm{L})^{-1} \cdot \mathrm{s}^{-1}$ and

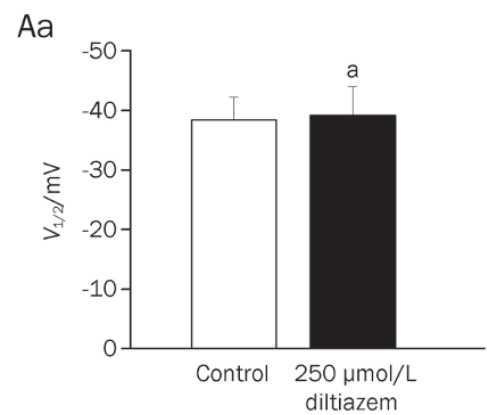

b
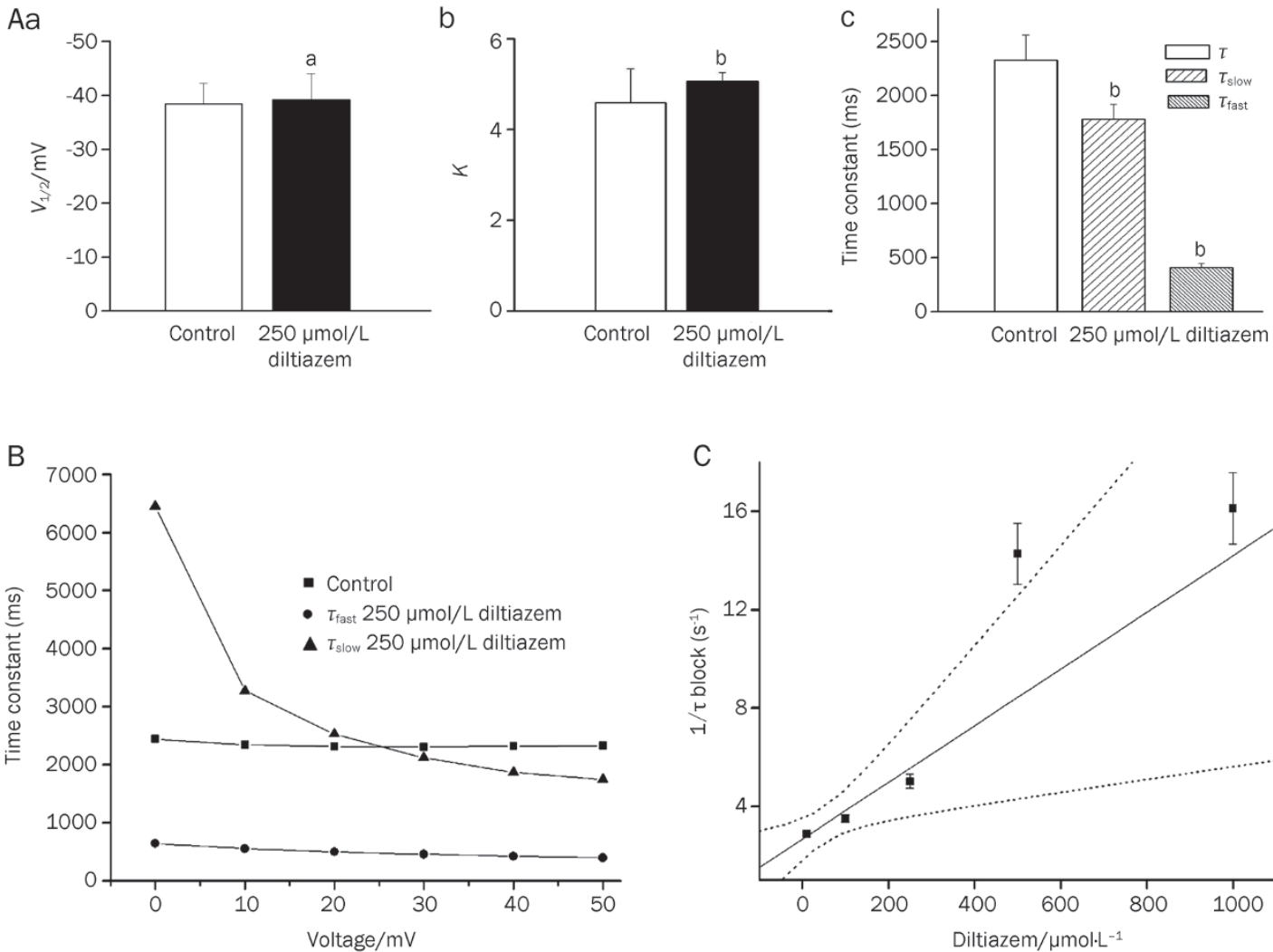

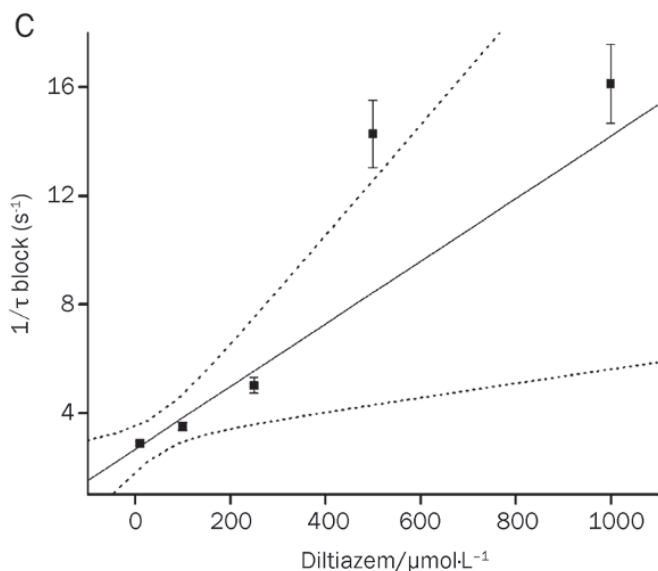

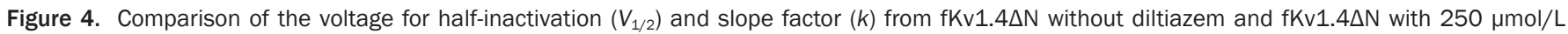
diltiazem (A(a) and $\mathrm{A}(\mathrm{b}))$. (A (a)) $V_{1 / 2, \text { control }}=-38.38 \pm 0.81 \mathrm{mV}(n=6), V_{1 / 2, \text { ditiazem }}=-39.23 \pm 0.85 \mathrm{mV}(n=6),(\mathrm{A}(\mathrm{b})) K_{\text {control }}=4.58 \pm 0.75(n=6), K_{\text {ditiazem }}=5.06 \pm 0.78$ $(n=6)$. Average data are shown as means \pm SEM ( ${ }^{a} P>0.05$ vs control), $(A(c))$ The effect of diltiazem on the rate of inactivation of fKv1.4 $\mathrm{N}$ channels. The time constant of inactivation was acquired by fitting the current trace elicited at $+50 \mathrm{mV}\left(\mathrm{P}_{1}\right)$ ranging from the beginning of the peak of $\mathrm{P}_{1}$ to the end of $5 \mathrm{~s} . \tau_{\text {inactivation, control }}=2.32 \pm 0.41 \mathrm{~s}(n=6)$. In the presence of diltiazem, $\tau_{\text {fast }}=0.41 \pm 0.04 \mathrm{~s}$ and $\tau_{\text {slow }}=1.78 \pm 0.29 \mathrm{~s}(n=6)$. Average data are shown as

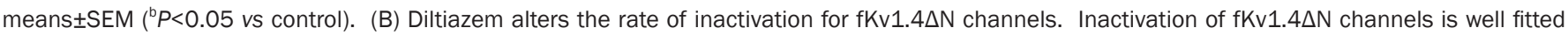
by a single exponential function (Chebyshev method), and is voltage independent ( $\mathbf{m}$ ) over the range $0 \mathrm{mV}$ to $+50 \mathrm{mV}$. In the presence of diltiazem, the inactivation of fKv1.4 $\mathrm{N}$ is best fitted with a bi-exponential function (Levenberg-Marquardt). Over the range $0 \mathrm{mV}$ to $+50 \mathrm{mV}$, $\tau_{\text {fast }}$ is voltage independent $(\bullet)$, whereas $\tau_{\text {slow }}$ is voltage dependent $(\boldsymbol{\Delta})$. (C) The reciprocal of the diltiazem-induced fast time constant $\left(1 / \tau_{\text {block }}\right)$ at $+50 \mathrm{mV}$ as a function of the diltiazem concentration for data obtained at concentrations in the range between $10 \mu \mathrm{mol} / \mathrm{L}$ and $1000 \mu \mathrm{mol} / \mathrm{L}$. The straight line is the least-squares fit to equation: $1 / \tau_{\text {block }}=k_{+1}[\mathrm{~d}]+k_{-1}$, where $\tau_{\text {block }}$ is the time constant of development of block, $k_{+1}$ and $k_{-1}$ are the apparent association rate constant and the apparent dissociation rate constant, respectively. The dotted lines is the 95\% confidence interval of the fit, each point represents the means $\pm S E M$ of 6 experiments. 
$2.67 \pm 0.25 \mathrm{~s}^{-1}$, respectively.

Effects of diltiazem on the recovery kinetics of fKv1.4AN currents The rate of recovery from inactivation of the Kv1.4 channel is governed by recovery from C-type inactivation. We measured the effect of diltiazem on the rate of recovery from inactivation in the fKv1.4 $\Delta \mathrm{N}$ channel using a standard gapped pulse protocol with a variable interstimulus interval. The ratio of the magnitude of the first and second pulse peak currents was used as an indication of the degree of the recovery from inactivation.

Figure 5A shows the fraction of fKv1.4 channels recovered plotted against the interstimulus interval. In the presence of
$250 \mu \mathrm{mol} / \mathrm{L}$ diltiazem, there is a dramatic decrease in the rate of recovery of fKv1.4 $\Delta \mathrm{N}$ channels when compared to the control. The envelope of peak ratios was best fitted with a monoexponential function. The presence of $250 \mu \mathrm{mol} / \mathrm{L}$ diltiazem increased the time constant for the rate of recovery from inactivation in $\mathrm{fKv} 1.4 \Delta \mathrm{N}$. The mean time constants for recovery were $1.73 \pm 0.10 \mathrm{~s}(n=5)$ in the control and 2.66 $\pm 0.14 \mathrm{~s}(n=5)$ in the diltiazem treated group $(P<0.05$; Figure $5 \mathrm{~B})$. The half time constant of recovery $\left(t_{1 / 2}\right)$ for fKv1.4 $\Delta \mathrm{N}$ was $1.01 \pm 0.03 \mathrm{~s}$ in the control and $1.67 \pm 0.05 \mathrm{~s}$ in the presence of $250 \mu \mathrm{mol} / \mathrm{L}$ diltiazem $(n=5, P<0.05$; Figure 6$)$. Diltiazem shifted the recovery from inactivation curve to the right and slowed the recovery time constant and $t_{1 / 2}$.
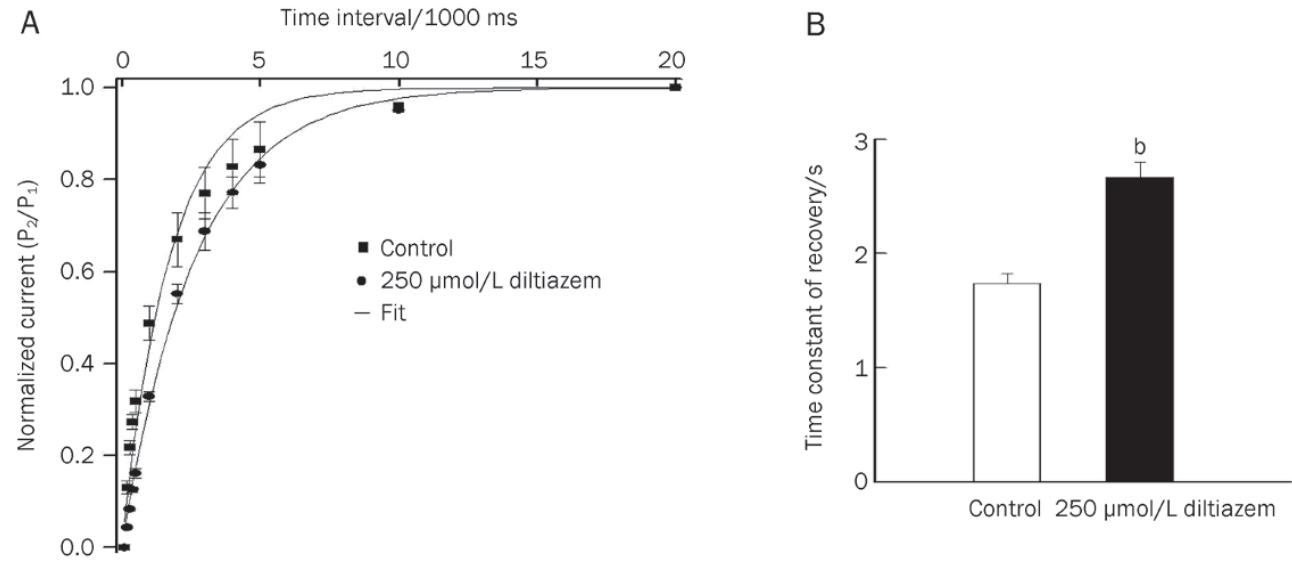

Figure 5. Effect of diltiazem on the rate of recovery from inactivation in fKv1.4 $\Delta \mathrm{N}$. Recovery from inactivation was measured using a standard variable interval gapped pulse protocol. An initial $5 \mathrm{~s}$ pulse $\left(P_{1}\right)$ from $-90 \mathrm{mV}$ to $+50 \mathrm{mV}$ was followed by a second pulse $\left(P_{2}\right)$ to $+50 \mathrm{mV}$ after an interval of between $0.1 \mathrm{~s}$ and $20 \mathrm{~s}$. (A) The ratio of the peak current elicited by the $P_{1}$ and $P_{2}$ pulses $\left(P_{2} / P_{1}\right)$ is plotted against pulse interval to show the recovery from inactivation. The recovery of inactivation was best fitted using the function: $f=1-A^{*} \exp (-\mathrm{T} / \mathrm{t}$ ), where $t$ is duration (in $\mathrm{S}$ ), $\mathrm{T}$ is the time constant, $\mathrm{A}$ is the amplitude of the current. Recovery curves for fKv1.4 $\Delta \mathrm{N}$ and fKv1.4 $\mathrm{N}$ +diltiazem, holding potential=-90 mV. (B) Comparison of recovery rate data from fKv1.4 $\Delta \mathrm{N}$ without and with $250 \mu \mathrm{mol} / \mathrm{L}$ diltiazem. The mean time constants for recovery were $1.73 \pm 0.10 \mathrm{~s}(n=5)$ in control and $2.66 \pm 0.14 \mathrm{~s}(n=5)$ in the diltiazem treated group $\left({ }^{\mathrm{b}} \mathrm{P}<0.05\right.$ vs control).
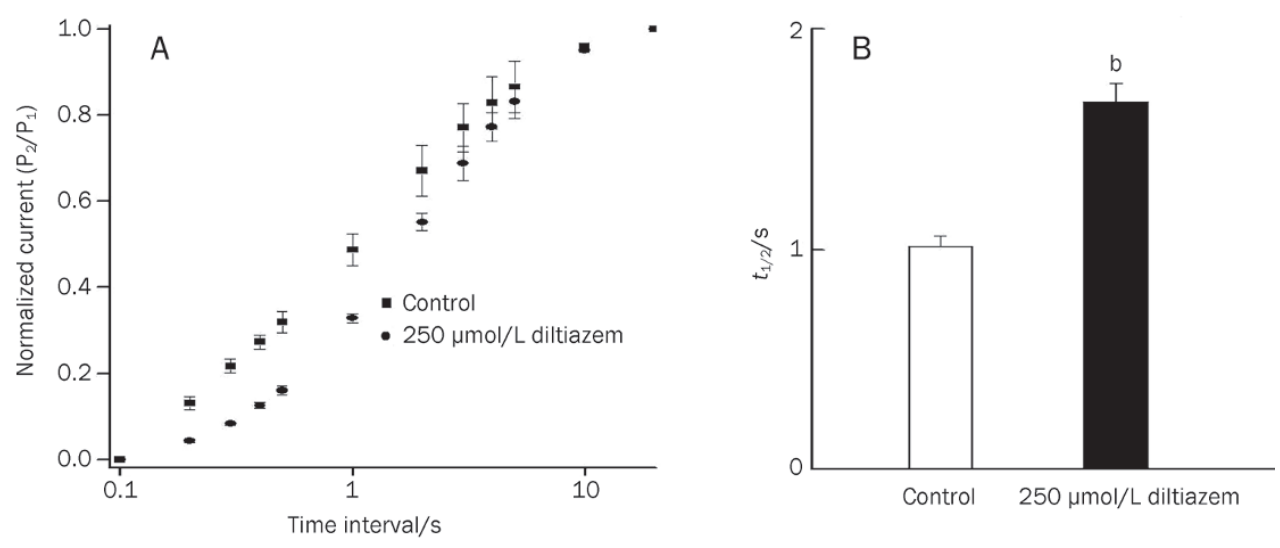

Figure 6. (A) Average recovery time course for fKv1.4 $\Delta \mathrm{N}$ without diltiazem and with $250 \mu \mathrm{mol} / \mathrm{L}$ diltiazem. Data were normalized between 0 and 1 presented with intervals on a log scale. (B) $t_{1 / 2}$ for fKv1.4 $\mathrm{N}$ was $1.01 \pm 0.03 \mathrm{~s}(n=5)$ and $t_{1 / 2}$ was $1.67 \pm 0.05 \mathrm{~s}(n=5)$ in the presence of $250 \mu \mathrm{mol} / \mathrm{L}$ diltiazem $\left({ }^{\mathrm{b}} \mathrm{P}<0.05\right.$ vs control). 
Effects of propafenone on fKv1.4 $\Delta \mathrm{N}$ currents Voltage-, concentration-, and frequency-dependent blockade of

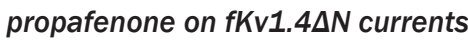

Figure 7A shows typical fKv1.4 $\mathrm{N}$ current traces recorded by applying $5 \mathrm{~s}$ pulses from $-100 \mathrm{mV}$ to $+50 \mathrm{mV}$ followed by the tail currents obtained upon repolarization to $+50 \mathrm{mV}$ under control conditions, in the presence of $100 \mu \mathrm{mol} / \mathrm{L}$ propafenone, and after the drug washout. As shown, 100 $\mu \mathrm{mol} / \mathrm{L}$ propafenone decreased $\mathrm{fKv} 1.4 \Delta \mathrm{N}$ currents, with the effect recovered upon a $10 \mathrm{~min}$ washout.

Peak-voltage relationships under control conditions, 100 $\mu \mathrm{mol} / \mathrm{L}$ propafenone, and after washout are shown in Figure 7B. In this figure, the $I_{\mathrm{PRO}} / I_{\mathrm{CON}}$ ratio is plotted as a function of the membrane potential. Propafenone substantially decreased the current amplitude at potentials positive to $-30 \mathrm{mV}$. The $I_{\mathrm{PRO}} / I_{\mathrm{CON}}$ ratio was plotted as a function of the membrane potential; the blockade increased steeply in the voltage range coinciding with that of channel activation (between $-40 \mathrm{mV}$ and $-20 \mathrm{mV}$ ), and it remained constant thereafter. The peak current was blocked by $51.82 \% \pm 2.35 \%$ when depolarized to $+50 \mathrm{mV}$ in $100 \mu \mathrm{mol} / \mathrm{L}$ propafenone, and the effect was reversed by $96 \%$ after the drug washout. There was a voltage dependence related to the action of propafenone, a phenomenon typical of open channel block.

The concentration dependence of open channel propafenone block of peak fKv1.4 $\Delta \mathrm{N}$ currents at $2 \mathrm{mmol} / \mathrm{L}\left[\mathrm{K}^{+}\right]_{\mathrm{o}}$ is shown in Figure 7C. Data were obtained upon repolarization to -90 $\mathrm{mV}$ after $1 \mathrm{~s}$ pulses to $+50 \mathrm{mV}$ (holding potential: $-90 \mathrm{mV}$ ). The concentration dependence of the blockade of $\mathrm{fKv} 1.4 \Delta \mathrm{N}$ currents was best fitted to the Hill equation. The $K_{\mathrm{D}}$ value for open channel block of fkv1.4 $\Delta \mathrm{N}$ was $103.68 \pm 11.25 \mu \mathrm{mol} / \mathrm{L}$ $(n=5)$.
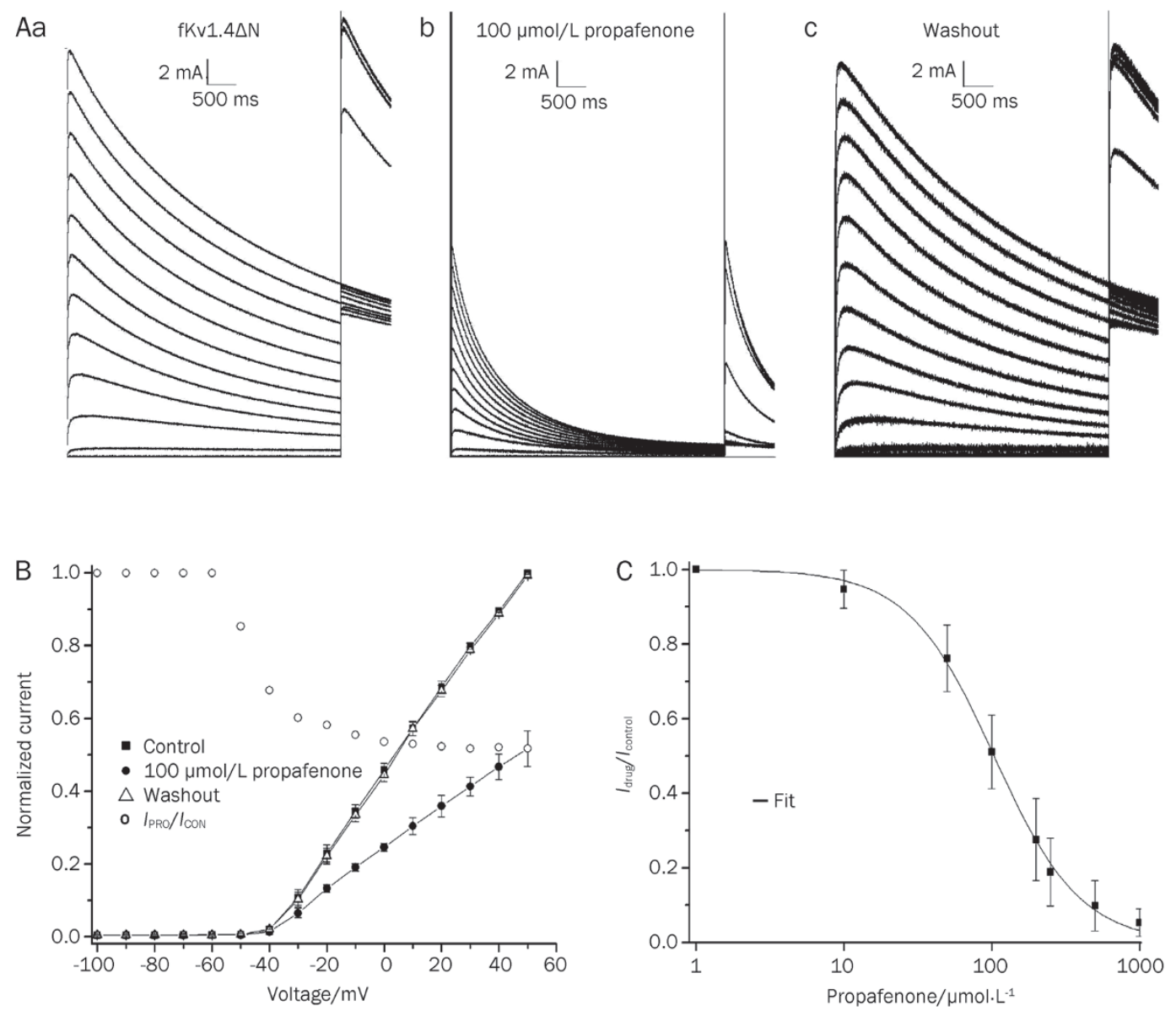

Figure 7. Voltage- and concentration-dependent blockade by propafenone on fKv1.4AN currents. (A) Current recordings from two-electrode voltage clamp of oocytes expressing fKv1.4AN. Currents were obtained by applying $5 \mathrm{~s}$ pulses to potentials $\left(\mathrm{P}_{1}\right)$ ranging from $-100 \mathrm{mV}$ to $+50 \mathrm{mV}$ followed by the tail currents obtained upon repolarization to $+50 \mathrm{mV}\left(\mathrm{P}_{2}\right)$ under control conditions (a), then in the presence of $100 \mu \mathrm{mol} / \mathrm{L}$ propafenone (b), and finally after $10 \mathrm{~min}$ of washout (c). (B) Current-voltage relationships of fKv1.4AN channels under control conditions, in the presence of $100 \mu \mathrm{mol} / \mathrm{L}$ propafenone, and after the drug washout for $10 \mathrm{~min}$. Currents were normalized to the peak current at $+50 \mathrm{mV}$ under control conditions. The $I_{\text {PRO }} / I_{\text {CON }}$ ratio was plotted as a function of the membrane potential. Data are shown as means \pm SEM $(n=5)$. (C) Dose-response relationships for propafenone inhibition of fKv1.4 $\Delta \mathrm{N}$ channels at $2 \mathrm{mmol} / \mathrm{L}\left[\mathrm{K}^{+}\right]_{0}$. Data were obtained upon repolarization to $-90 \mathrm{mV}$ after $1 \mathrm{~s}$ pulses to $+50 \mathrm{mV}$, holding potential -90 $\mathrm{mV}$. All values shown were normalized to the peak current in the absence of drug in $2 \mathrm{mmol} / \mathrm{L}\left[\mathrm{K}^{+}\right]_{0}$. Continuous line was derived by fitting the data to the Hill equation: $f=K_{D} /\left(K_{D}+D\right)$, where $f$ is fractional current, $K_{D}$ is the apparent dissociation constant, and $D$ is the propafenone concentration. Symbols and error bar are means \pm SEM. fKv1.4AN current was reduced to $50 \%$ by $103.68 \pm 11.25 \mu \mathrm{mol} / \mathrm{L}$. 
To determine the longer-term effects of exposing the $\mathrm{fKv} 1.4 \Delta \mathrm{N}$ channel to propafenone, we applied a series of 500 ms depolarizing pulses from $-90 \mathrm{mV}$ to $+50 \mathrm{mV}$ with a frequency of $1 \mathrm{~Hz}$ for a period of $1 \mathrm{~min}$. Figure 8 shows the peak currents recorded by this protocol, before and after exposure to $100 \mu \mathrm{mol} / \mathrm{L}$ propafenone, normalized to the first peak current under control conditions. With increasing pulse numbers, the currents in both the control and the propafenone-treated groups decreased. The first pulse of the pulse train in the presence of $100 \mu \mathrm{mol} / \mathrm{L}$ propafenone showed a decrease relative to the pre-drug control, and the magnitude of this reduction was similar to that seen under steady-state conditions when an adequately long recovery time was allowed between test pulses. In both the control and the $100 \mu \mathrm{mol} / \mathrm{L}$ propafenone protocols, there was a use-dependent decrease in the peak current when stimulated at $1 \mathrm{~Hz}$, but this use-dependent decrease was much greater in $100 \mu \mathrm{mol} / \mathrm{L}$ propafenone than in the control. In control oocytes, the peak current decayed mono-exponentially from $100 \%$ to $74.52 \%$. By contrast, in $100 \mu \mathrm{mol} / \mathrm{L}$ propafenone, the current decreased from $49.72 \%$ (due to initial rapid open channel block) to $35.20 \%$ in the steady state.

\section{Effect of propafenone on the steady inactivation of peak Kv1.4AN currents}

The time-dependent progression of the channel from the rapid open block conformation into a propafenone-induced block was studied during a single depolarizing step from $-90 \mathrm{mV}$ to +50 mV (Figure 9A). For comparison, all current traces were normalized to the peak values under control conditions. In control conditions, the rate of inactivation of $\mathrm{fKv} 1.4 \Delta \mathrm{N}$ was mono-exponential with a time constant of $2.32 \pm 0.41 \mathrm{~s}(n=6)$. In the presence of 10 to $500 \mu \mathrm{mol} / \mathrm{L}$ propafenone, inactivation became bi-exponential, with a dominant fast exponential.

Figure $9 \mathrm{~B}(\mathrm{a})$ shows the inactivation curves in the absence and presence of $100 \mu \mathrm{mol} / \mathrm{L}$ propafenone. The steady-state inactivation relationships were determined from the two pulse protocol by calculating the ratio of the magnitude of the peak current in $\mathrm{P}_{2}$ to the maximum of the $\mathrm{P}_{2}$ obtained when $\mathrm{P}_{1}$ was $-100 \mathrm{mV}$. In this panel, propafenone can be seen to shift the voltage dependence of inactivation to the left. However, after steady-state inactivation relationships were renormalized [Figure 9B(b)], we found that propafenone did not shift the voltage dependence of inactivation. Under control conditions, the $V_{1 / 2}$ and $K$ values averaged $-41.29 \pm 5.21 \mathrm{mV}$ and $1.13 \pm 0.09$ $(n=6)$, and $100 \mu \mathrm{mol} / \mathrm{L}$ propafenone did not modify either the $V_{1 / 2}(-50.62 \pm 6.77 \mathrm{mV})$ or the $K(1.62 \pm 0.27)(n=6)$ [Figure $10 \mathrm{~A}(\mathrm{a}$ and b)].

Inactivation of $\mathrm{fKv} 1.4 \Delta \mathrm{N}$ is best fitted by a single exponential function (Figure 10B), with $\tau_{\text {inactivation }}=2.32 \pm 0.41 \mathrm{~s}(n=6)$ at $+50 \mathrm{mV}$. In the presence of propafenone, the inactivation of $\mathrm{fKv} 1.4 \Delta \mathrm{N}$ is best fitted with a bi-exponential function, with $\tau_{\text {fast }}=0.44 \pm 0.03 \mathrm{~s}$ and $\tau_{\text {slow }}=2.23 \pm 0.23 \mathrm{~s}(n=6)$ at $+50 \mathrm{mV}$ [Figure $10 \mathrm{~A}(\mathrm{c})]$. We found that $\mathrm{C}$-type inactivation was not shifted by $100 \mu \mathrm{mol} / \mathrm{L}$ propafenone at $+50 \mathrm{mV}$. Over the range of $0 \mathrm{mV}$ to $+50 \mathrm{mV}$, there was no voltage sensitivity to $\tau_{\text {inactivation }}(P>0.05$, $n=6)$. In the presence of propafenone, both $\tau_{\text {fast }}$ and $\tau_{\text {slow }}$ were voltage independent.

Figure 10C shows the plot of the $1 / \tau_{\text {block }}$ as a function of the propafenone concentration for data obtained at concentrations between $10 \mu \mathrm{mol} / \mathrm{L}$ and $500 \mu \mathrm{mol} / \mathrm{L}$. The straight line is the least-squares fit to the equation $\left(1 / \tau_{\text {block }}=k_{+1}[\mathrm{~d}]+k_{-1}\right)$, and the apparent association and dissociation rate constants were $(0.02 \pm 0.002) \times 10^{6}(\mathrm{~mol} / \mathrm{L})^{-1} \cdot \mathrm{s}^{-1}$ and $1.87 \pm 0.15 \mathrm{~s}^{-1}$, respectively.

\section{Effects of propafenone on the recovery kinetics of fKv1.4AN currents}

The effects of propafenone on the recovery kinetics of the $\mathrm{fKv} 1.4 \Delta \mathrm{N}$ channel expressed in Xenopus oocytes are presented in Figure 11A. The fraction of fKv1.4 channels recovered was plotted against the interstimulus interval. The mean time constants of recovery from the steady-state inactivation were $1.78 \pm 0.09 \mathrm{~s}(n=5)$ in the control and $1.86 \pm 0.14 \mathrm{~s}(n=5)$ in the propafenone treated group $(P>0.05$; Figure $11 \mathrm{~B})$. In the presence of $100 \mathrm{\mu mol} / \mathrm{L}$ propafenone, there is no significant change in the rate of recovery of $\mathrm{fKv} 1.4 \Delta \mathrm{N}$ compared to the control. The half time constant of recovery for $f K v 1.4 \Delta \mathrm{N}$ was $1.14 \pm 0.04 \mathrm{~s}$ in the control and $1.49 \pm 0.05 \mathrm{~s}$ in the presence of 100 $\mu \mathrm{mol} / \mathrm{L}$ propafenone $(n=5, P>0.05$; Figure 12$)$. These results
A

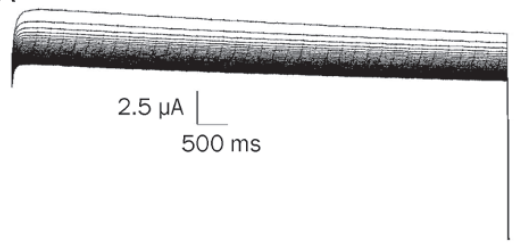

B

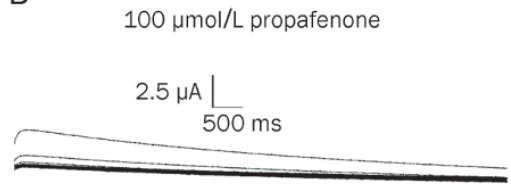

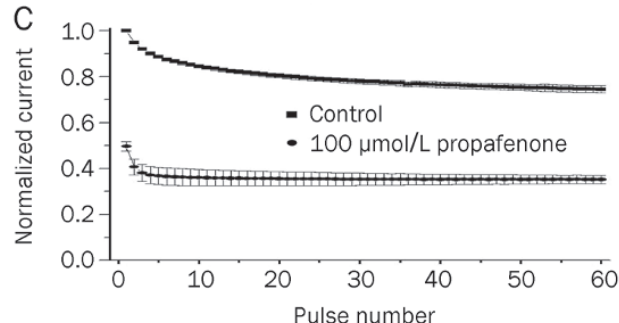

Figure 8. Frequency-dependent block of fKv1.4AN channel by propafenone. Currents were elicited by using a series of depolarising pulses from - 90 $\mathrm{mV}$ to $+50 \mathrm{mV}$ with a frequency of $1 \mathrm{~Hz}$ in the absence (A) and in the presence of $100 \mu \mathrm{mol} / \mathrm{L}$ propafenone (B). The peak currents shown in Panel $\mathrm{A}$ and $\mathrm{B}$ were normalized to the maximum control value without drug and plotted in Panel $\mathrm{C}$. As pulse number increased, currents in both control and propafenone-treated groups decreased. In control cells, there was a use-dependent reduction in the magnitude of the peak current. When cells were exposed to $100 \mu \mathrm{mol} / \mathrm{L}$ propafenone for $10 \mathrm{~min}$ before stimulation, there was a reduction in the magnitude of the first peak current compared to the control value and then a use-dependent component. The use-dependent reduction in current with propafenone was obviously greater than that seen in control. 

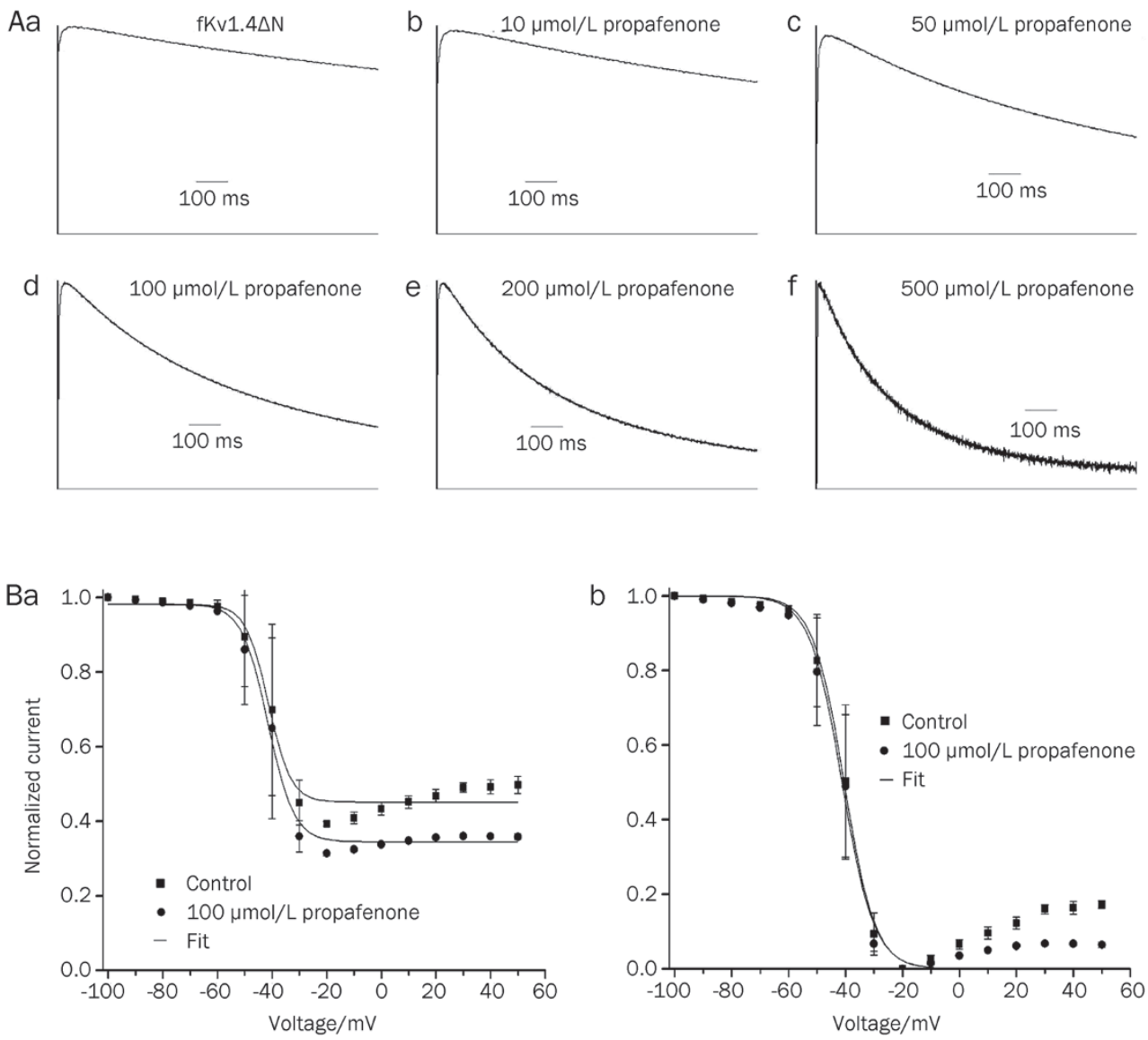

Figure 9. Effect of propafenone on the steady inactivation of peak Kv1.4AN currents. (A) The time-dependent progression of channel currents. Currents were recorded by using $1 \mathrm{~s}$ pulses from $-90 \mathrm{mV}$ to $+50 \mathrm{mV}$ in the absence and presence of increasing concentrations of propafenone. For comparison, all current traces were normalized to the peak values under control conditions. The smooth continuous line superimposed on each trace is the best fit of an exponential function, used to determine the inactivation time constant (s). The control trace was best fitted by a mono-exponential function (Chebyshev method) (a), whereas in the presence of $10-500 \mu \mathrm{mol} / \mathrm{L}$ propafenone, inactivation was best fitted by a bi-exponential function (Levenberg-Marquardt) (b-f). (B) Steady-state inactivation relationships (a). The steady-state inactivation for each $P_{1}$ voltage was calculated as the magnitude of the peak current in $P_{2}$ compared with that from the maximum of the $P_{2}$ obtained when $P_{1}$ was $-100 \mathrm{mV}$. Average data are shown as

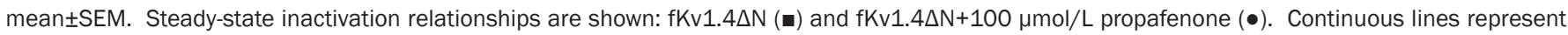
the fit of the data to a Boltzmann equation: $\left.f=1 /\left\{1+\exp *\left[\left(V-V_{1 / 2}\right) / k\right)\right]\right\}$. Steady-state inactivation relationships were re-normalized (b).

indicate that propafenone does not affect the recovery of fKv1.4 $\Delta \mathrm{N}$ channels from inactivation.

\section{Discussion}

The L-type calcium channel blocker diltiazem and the sodium channel blocker propafenone have been reported to block several cloned potassium channels, including Kv1.1, Kv1.2, Kv1.4, Kv1.5, Kv2.1, Kv4.2, and hERG channel currents ${ }^{[16,21-24]}$. For instance, diltiazem, at concentrations of $0.01 \mathrm{nmol} / \mathrm{L}$ to 500 $\mu \mathrm{mol} / \mathrm{L}$, suppressed the hKv1.5 potassium channel expressed in mouse fibroblasts with an estimated $\mathrm{IC}_{50}$ of $42.3 \mu \mathrm{mol} / \mathrm{L}^{[17]}$. But in human atrial myocytes, $I_{\text {Kur }}$ was blocked by diltiazem at relatively low concentrations $\left(\mathrm{IC}_{50}=11.2 \mu \mathrm{mol} / \mathrm{L}\right)^{[25]}$. In Chinese hamster ovary cells, diltiazem $(109.9 \mu \mathrm{mol} / \mathrm{L})$ was reported to suppress the Kv4.3 channel by $50 \%{ }^{[17]}$. Diltiazem blocked $I_{\text {to }}$ (fast) in human atrial myocytes with an $\mathrm{IC}_{50}$ of 29.2 $\mu \mathrm{mol} / \mathrm{L}^{[26]}$. Propafenone was shown to depress hERG chan- nel currents in human embryonic kidney cells with an $\mathrm{IC}_{50}$ of $440 \mu \mathrm{mol} / \mathrm{L}^{[22]}$, and it was shown to block hKv1.5 channels in a concentration-, voltage-, time- and use-dependent manner with an $\mathrm{IC}_{50}$ value of $4.4 \mathrm{mmol} / \mathrm{L}^{[23]}$. Propafenone was also shown to inhibit $I_{\text {to }}$ in rabbit atrial myocytes and rat ventricular myocytes ${ }^{[26]}$, as well as to inhibit the hyperpolarizationactivated inward current in isolated human atrial myocytes ${ }^{[27]}$ and $I_{\mathrm{Kr}}$ in sinoatrial node cells, rabbit atrial myocytes and guinea pig ventricular myocytes ${ }^{[26,28-29]}$.

Limited data are available for the Kv1.4 potassium channel. In Xenopus oocytes, diltiazem and propafenone have been reported to reduce fKv1.4 potassium channel currents, and $100 \mu \mathrm{mol} / \mathrm{L}$ diltiazem and $100 \mu \mathrm{mol} / \mathrm{L}$ propafenone were reported to suppress Kv1.4 potassium channel tail currents by $10 \%$ and $11 \%$, respectively ${ }^{[16]}$. Propafenone was shown to be an open channel antagonist of Kv1.4 channel currents ${ }^{[18]}$, but the mechanism of the drug block was not examined. Our find- 

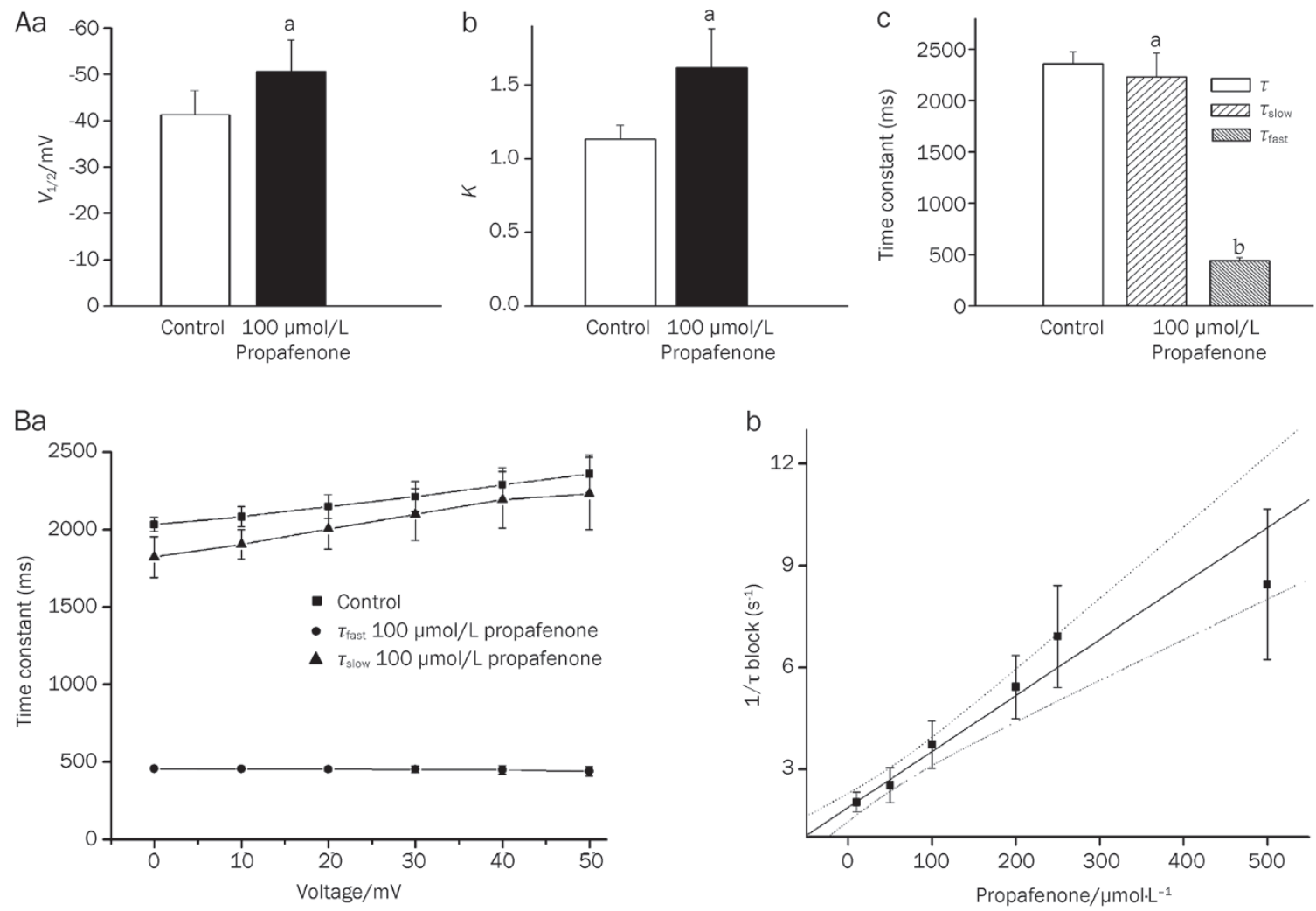

Figure 10. Comparison of the voltage for $V_{1 / 2}$ and $K$ from fKv1.4 $\Delta N$ without propafenone and fKv1.4 $\Delta N$ with $100 \mu$ mol/L propafenone $[A(a)$ and $A(b)]$. $[\mathrm{A}(\mathrm{a})] V_{1 / 2 \text {, control }}=-41.29 \pm 5.21 \mathrm{mV}(n=6), V_{1 / 2, \text { propafenone }}=-50.62 \pm 6.77 \mathrm{mV}(n=6) ;[\mathrm{A}(\mathrm{b})] K_{\text {control }}=1.13 \pm 0.09(n=6), K_{\text {propafenone }}=1.62 \pm 0.27(n=6) ;[\mathrm{A}(\mathrm{c})] \mathrm{The}$ effect of propafenone on the rate of inactivation of fKv1.4AN channels. The time constant of inactivation was acquired by fitting the current trace elicited at $+50 \mathrm{mV}\left(\mathrm{P}_{1}\right)$ ranging from the beginning of the peak of $\mathrm{P}_{1}$ to the end of $5 \mathrm{~s}$. $\tau_{\text {inactivation, control }}=2.32 \pm 0.41 \mathrm{~s}(n=6)$. In the presence of propafenone, $\tau_{\text {fast }}=0.44 \pm 0.03 \mathrm{~s}$ and $\tau_{\text {slow }}=2.32 \pm 0.23 \mathrm{~s}(n=6)$. Average data are shown as means \pm SEM $\left({ }^{\mathrm{a}} P>0.05,{ }^{\mathrm{b}} P<0.05 \mathrm{vs}\right.$ control). (B) Effect of propafenone on

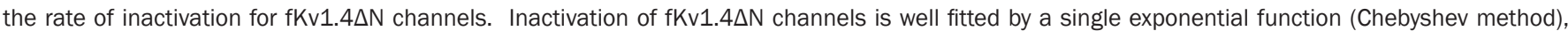
and is voltage independent ( - ) over the range of $0 \mathrm{mV}$ to $+50 \mathrm{mV}$. In the presence of propafenone, the inactivation of fKv1.4 $\Delta \mathrm{N}$ is best fitted with a biexponential function (Levenberg-Marquardt). Over the range of $0 \mathrm{mV}$ to $+50 \mathrm{mV}$, both $\tau_{\text {fast }}(\bullet)$ and $\tau_{\text {slow }}(\boldsymbol{\Delta})$ are voltage independent. (C) The reciprocal of the propafenone-induced fast time constant $\left(1 / \tau_{\text {block }}\right)$ at $+50 \mathrm{mV}$ as a function of the propafenone concentration for data obtained at concentrations in the range between 10 and $500 \mu \mathrm{mol} / \mathrm{L}$. The straight line is the least-squares fit to equation: $1 / \tau_{\text {block }}=k_{+1}[\mathrm{~d}]+k_{-1}$, where $\tau_{\text {block }}$ is the time constant of development of block, $k_{+1}$ and $k_{-1}$ are the apparent association rate constant and the apparent dissociation rate constant, respectively. The dotted lines is the $95 \%$ confidence interval of the fit, each point represents the means \pm SEM of 6 experiments.

ings agree with these reports; however, we found that blockade required relatively high drug concentrations.

In the current study, it has been shown that both diltiazem and propafenone are blockers of the fKv1.4 channel. Starting with concentrations of $10 \mu \mathrm{mol} / \mathrm{L}$, up to $50 \%$ of the fKv1.4 channel currents were blocked with $241 \mu \mathrm{mol} / \mathrm{L}$ diltiazem and $103 \mu \mathrm{mol} / \mathrm{L}$ propafenone. Although the concentrations required were higher, in interpreting the results, it has to be further considered that in the oocyte expression system, a fivefold to ten fold higher concentration of antiarrhythmic drugs is needed to obtain an effect comparable to that seen in mammalian cells lines ${ }^{[16]}$. Thus, it can be assumed that in cardiomyocytes, both diltiazem and propafenone have an even stronger effect on the Kv1.4 channel than that reported in this study in Xenopus oocytes.

Diltiazem and propafenone are different types of antiarrhythmic drugs. The electrophysiological effects of the two drugs on $\mathrm{fKv} 1.4 \Delta \mathrm{N}$ channel inactivation have been determined. Both drugs decrease $\mathrm{fKv} 1.4 \Delta \mathrm{N}$ channel currents in voltage-, concentration-, and frequency-dependent manners. However, the difference between the two drugs is three fold. First, our results have demonstrated that diltiazem exhibits a similarly high affinity for fKv1.4 channels and that the concentration of blockade is slightly higher than that needed to block L-type calcium channels ${ }^{[16]}$, while propafenone exhibits a higher binding affinity for fKv1.4 channels compared with diltiazem. Second, in the presence of diltiazem, the magnitude of the peak current is obviously reduced, and the rate of inactivation is increased compared with the control. The $\tau_{\text {inactivation }}$ values we found were $2.32 \pm 0.21 \mathrm{~s}$ and $1.78 \pm 0.19 \mathrm{~s}$ in the absence and presence of $250 \mu \mathrm{mol} / \mathrm{L}$ diltiazem, respectively; however, $100 \mu \mathrm{mol} / \mathrm{L}$ propafenone did not increase the C-type inactivation time constant. Third, diltiazem slows recovery from inactivation, but propafenone has no effect on this process. 

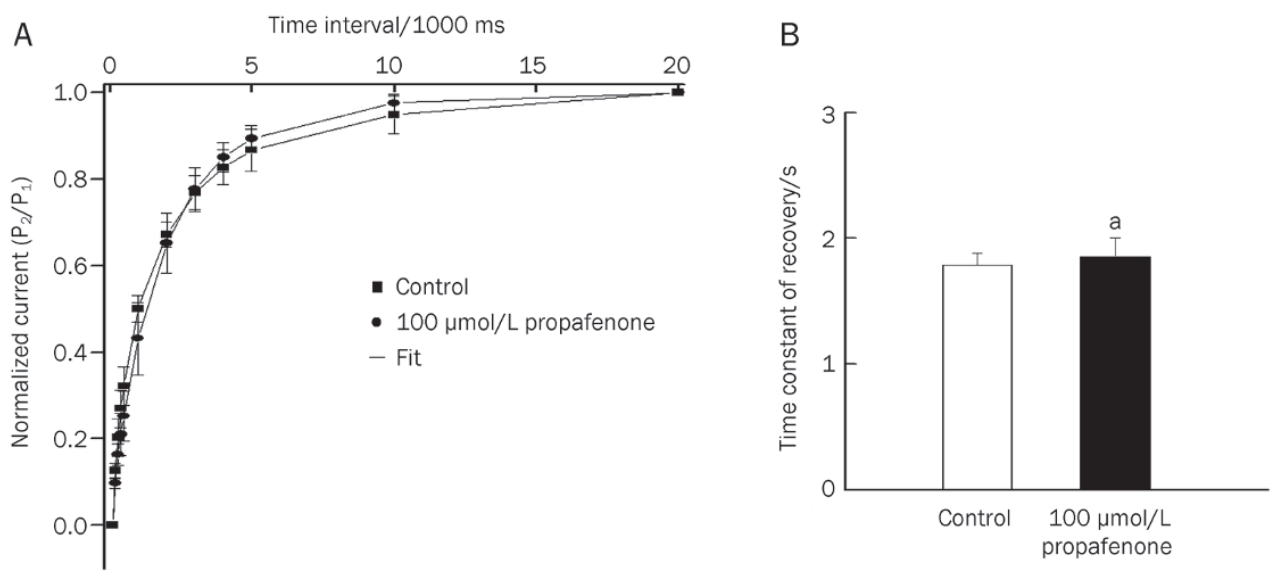

Figure 11. Effect of propafenone on the rate of recovery from inactivation in fKv1.4AN. Recovery from inactivation was measured using a standard variable interval gapped pulse protocol. An initial $5 \mathrm{~s}$ pulse $\left(\mathrm{P}_{1}\right)$ from $-90 \mathrm{mV}$ to $+50 \mathrm{mV}$ was followed by a second pulse $\left(\mathrm{P}_{2}\right)$ to $+50 \mathrm{mV}$ after an interval between 0.1 and $20 \mathrm{~s}$. (A) The ratio of the peak current elicited by the $P_{1}$ and $P_{2}$ pulses $\left(P_{2} / P_{1}\right)$ is plotted against pulse interval to show the recovery from inactivation. The recovery of inactivation was best fitted using the function: $f=1-A^{*} \exp (-\tau / t)$, where $t$ is duration (in $\mathrm{s}$ ), $\tau$ is the time constant, $A$

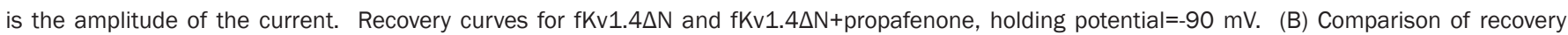
rate data from fKv $1.4 \Delta \mathrm{N}$ without and with $100 \mu \mathrm{mol} / \mathrm{L}$ propafenone. The mean time constants for recovery were $1.78 \pm 0.09 \mathrm{~s}(n=5)$ in control and $1.86 \pm 0.14 \mathrm{~s}(n=5)$ in the propafenone treated group $\left({ }^{\mathrm{a}} \mathrm{P}>0.05 \mathrm{vs}\right.$ control).
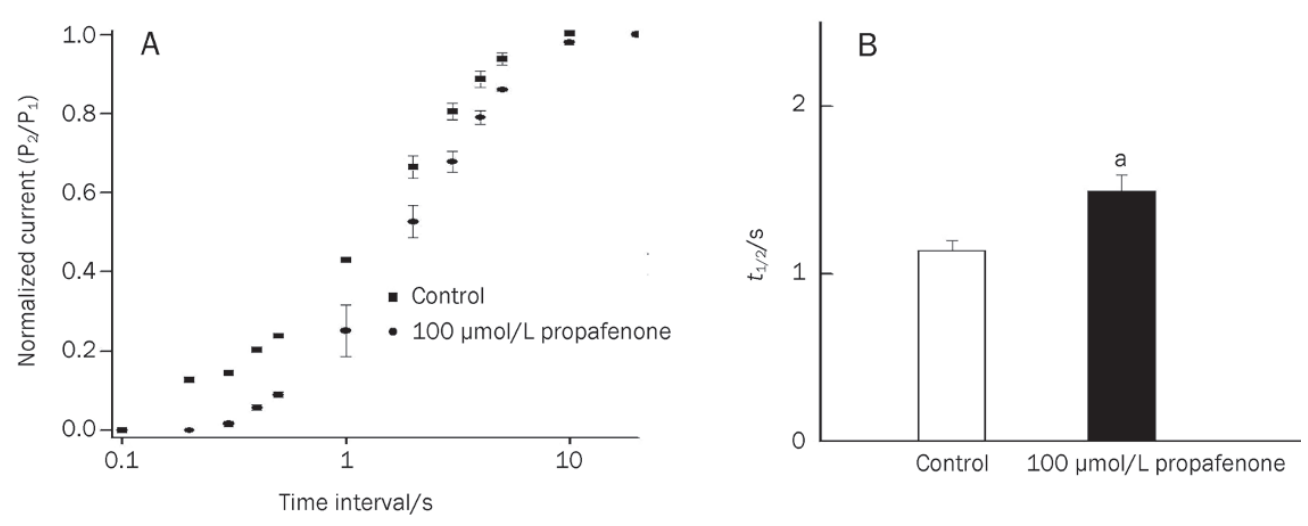

Figure 12. (A) Average recovery time course for fKv1.4 $\Delta \mathrm{N}$ without propafenone and with $100 \mu \mathrm{mol} / \mathrm{L}$ propafenone. Data were normalized between

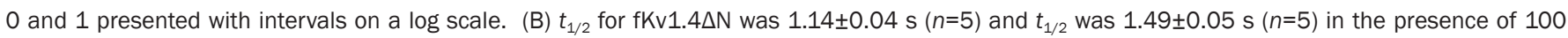
$\mu \mathrm{mol} / \mathrm{L}$ propafenone $\left({ }^{\mathrm{a}} \mathrm{P}>0.05\right.$ vs control).

Diltiazem induced a voltage-dependent block of fKv1.4 channels that increased over the voltage range of channel activation. When channel activation reached saturation, the block induced by diltiazem remained increased, an effect that resembles the action of propafenone on $\mathrm{fKv} 1.4^{[18]}$, and there was a voltage dependence to the action of both drugs.

The rate of fKv1.4 current decay in the control could be fitted to a single exponential function, and in the presence of diltiazem and propafenone, the inactivation became biexponential, characterized by the extremely fast drug-induced inactivation and the relatively slower C-type inactivation. The diltiazem-induced C-type inactivation was much faster than that seen under control conditions, which may be explained by the mechanism in which binding of drug to the intracellular site of the channel triggers a conformational change at the external mouth of the pore that facilitates C-type inactivation. This phenomenon was also observed in the same channel induced by quinidine and verapamil ${ }^{[18,20]}$. However, propafenone did not increase the C-type inactivation time constant, demonstrating that binding of propafenone to the channel did not induce a conformational change at the external mouth of the pore.

The two drug-induced extra component of inactivation [rapid inactivation $\left.\left(\tau_{\text {fast }}\right)\right]$ had a time constant that was much faster than that of slow inactivation; therefore, this fast time constant can be considered to represent the interaction of the drug with the open state. Using the time constants of development for fKv1.4 blockade obtained in the range of 10-1000 $\mu \mathrm{mol} / \mathrm{L}$ (for diltiazem) and 10-500 $\mu \mathrm{mol} / \mathrm{L}$ (for propafenone), the $k_{+1}$ and $k_{-1}$ constants for diltiazem and propafenone were obtained. Assuming a first order reaction drug/channel inter- 
action, the ratio $k_{-1} / k_{+1}$ would give the apparent $\mathrm{IC}_{50}$ of 267 $\mu \mathrm{mol} / \mathrm{L}$ (for diltiazem) and $113 \mu \mathrm{mol} / \mathrm{L}$ (for propafenone) ${ }^{[30,31]}$. This estimate was independent of but similar to the $\mathrm{IC}_{50}$ calculated from the respective concentration-response curve. The similarity of the $\mathrm{IC}_{50}$ values obtained by the two independent methods supports the open-channel block model used to calculate the rate constants for the Kv1.4 channel. Diltiazem and propafenone-induced blockade of Kv1.4 channels developed during depolarization, and no blockade happened when the channel closed, which strongly suggests that both drugs are open state blockers of the Kv1.4 channel.

From this study, we found that diltiazem blockade of the fKv1.4 $\Delta \mathrm{N}$ channel was a complex process that may involve more than one conformational state. First, diltiazem blocks the open channel with rapid kinetics as fast as activation kinetics because diltiazem does not change the steady state activation. Second, diltiazem binds to the channel and blocks it in a voltage- and time-dependent manner. Finally, the binding of diltiazem to the channel enhances C-type inactivation. Based on previous results showing that retardation of C-type inactivation dramatically reduced E-4031 binding affinity in hERG channels ${ }^{[32]}$, we concluded that an interaction between drug binding and C-type inactivation exists.

Clinically, diltiazem is widely used as an anti-arrhythmic and anti-anginal drug. It has been reported that the cardiac action potentials in mice were lengthened by $10 \mathrm{nmol} / \mathrm{L}$ diltiazem, a finding that may be explained by diltiazem-induced blockade of the $I_{\text {to }}$ (slow) currents generated by the Kv1.4 channel ${ }^{[33]}$. The Kv1.4 channel, as the major component of $I_{\mathrm{to}}$ (slow), which in turn is a major contributor to phase 1 and the early part of phase 2 of the action potential, plays an important role in the repolarization of the endocardial region of the left ventricle ${ }^{[34]}$. Therefore, the reduction of Kv1.4 induced by diltiazem prolongs action potential durations. Propafenone has a similar effect.

In this study, we found that in response to the faster frequency stimulations, fKv1.4 $\Delta \mathrm{N}$ channel currents were significantly reduced. Opening the channel with a faster frequency may facilitate entry of the drug into the channel. These conformation-specific drug-binding properties lead to some clinically important issues, such as use dependence. The effects of micromolar diltiazem on fKv1.4 are moderate but are likely to be enhanced during tachyarrhythmias due to the frequency dependence of the drug's action, and propafenone shares these characteristics. Decreasing recovery rates could attenuate the shortening of the action potential duration caused by diltiazem-induced inhibition of L-type calcium channels. Because diltiazem and propafenone have different antiarrhythmic effects, their blockade actions on the Kv1.4 $\Delta \mathrm{N}$ channel must be considered when diltiazem is applied in combination with propafenone or other potassium channel blockers such as amiodarone.

\section{Acknowledgements}

We thank Dr RASMUSSON (University at Buffalo, SUNY) for the fKv1.4 $\triangle \mathrm{N}$ cDNA.

\section{Author contribution}

Dong ZHANG, Hui CHEN, and Shi-min WANG designed the research; Dong ZHANG, Hui CHEN, Sheng-ping CHAO, and Xue-jun JIANG performed the research; Dong ZHANG and Shi-min WANG analyzed the data; Dong ZHANG and Hui CHEN wrote the paper.

\section{References}

1 Campbell DL, Rasmusson RL, Qu Y, Strauss HC. The calciumindependent transient outward potassium current in isolated ferret right ventricular myocytes. I. Basic characterization and kinetic analysis. J Gen Physiol 1993; 101: 60-6.

2 Greenstein JL, Wu R, Po S, Tomaselli GF, Winslow RL. Role of the calcium-independent transient outward current Ito 1 in shaping action potential morphology and duration. Circ Res 2000; 87: 1026-33.

3 Wettwer E, Amos GJ, Posival H, Ravens U. Transient outward current in human ventricular myocytes of subepicardial and subendocardial origin. Circ Res 1994; 75: 473-82.

4 Holmgren M, Jurman ME, Yellen G. N-type inactivation and the S4-S5 region of the Shaker $\mathrm{K}^{+}$channel. J Gen Physiol 1996; 108: 195-206.

5 Hoshi T, Zagotta WN, Aldrich RW. Biophysical and molecular mechanisms of Shaker potassium channel inactivation. Science 1990; 250: 533-8.

6 Isacoff EY, Jan YN, Jan LY. Putative receptor for the cytoplasmic inactivation gate in the Shaker $\mathrm{K}^{+}$channel. Nature 1991; 353: 8690.

7 Jerng $\mathrm{HH}$, Covarrubias $\mathrm{M}$. $\mathrm{K}^{+}$channel inactivation mediated by the concerted action of the cytoplasmic $\mathrm{N}$ - and $\mathrm{C}$-terminal domains. Biophys J 1997; 72: 163-74.

8 Lopez GA, Jan YN, Jan LY. Evidence that the S6 segment of the Shaker voltage-gated $\mathrm{K}^{+}$channel comprises part of the pore. Nature 1994; 367: 179-82.

9 Zagotta WN, Hoshi T, and Aldrich RW. Restoration of inactivation in mutants of Shaker potassium channels by a peptide derived from ShB. Science 1990; 250: 568-71.

10 Liu Y, Jurman ME, Yellen G. Dynamic rearrangement of the outer mouth of a K $\mathrm{K}^{+}$channel during gating. Neuron 1996; 16: 859-67.

11 Rasmusson RL, Morales MJ, Castellino RC, Zhang Y, Campbell DL, Strauss HC. C-type inactivation controls recovery in a fast inactivating cardiac $\mathrm{K}^{+}$channel (Kv1.4) expressed in Xenopus oocytes. J Physiol 1995; 489: 709-21.

12 Kumar S, Hall RJ. Drug treatment of stable angina pectoris in the elderly: defining the place of calcium channel antagonists. Drugs Aging 2003; 20: 805-15.

13 Hohnloser SH, Kuck KH, Lilienthal J. Rhythm or rate control in atrial fibrillation -pharmacological intervention in atrial fibrillation (PIAF): a randomised trial. Lancet 2000; 356: 1789-94.

14 Gorenek B, Cavusoglu Y, Goktekin O, Birdane A, Kudaiberdieva $\mathrm{G}$, Ata $\mathrm{N}$, et al. Amiodarone versus sotalol and propafenone for prevention of immediate recurrence of atrial fibrillation after internal cardioversion: importance of $\mathrm{P}$ wave analysis. Int J Cardiol 2006; 106: 268-9.

15 Grissmer S, Nguyen AN, Aiyar J, Hanson DC, Mather RJ, Gutman GA, et al. Pharmacological characterization of five cloned voltage gated $\mathrm{K}^{+}$channels, types $\mathrm{Kv1.1}, 1.2,1.3,1.5$, and 3.1, stably expressed in mammalian cell lines. Mol Pharmacol 1994; 45: 1227-34.

16 Rolf S, Haverkamp W, Borggrefe M, Musshoff U, Eckardt L, Mergenthaler J, et al. Effects of antiarrhythmic drugs on cloned cardiac voltage-gated potassium channels expressed in Xenopus oocytes. Naunyn Schmiedebergs Arch Pharmacol 2000; 362: 22-31. 
17 Caballero R, Gómez R, Núñez L, Moreno I, Tamargo J, Delpón E. Diltiazem inhibits hKv1.5 and Kv4.3 currents at therapeutic concentrations. Cardiovasc Res 2004; 64: 457-66.

18 Xu L, Huang C, Chen J, Jiang X, Li X, Bett GC, et al. Effect of amiodarone on Kv1.4 channel C-type inactivation: comparison of its effects with those induced by propafenone and verapamil. Pharmazie 2008; 63: 475-9.

19 Comer MB, Campbell DL, Rasmusson RL, Lamson DR, Morales MJ, Zhang $\mathrm{Y}$, et al. Cloning and characterization of an Ito-like potassium channel from ferret ventricle. Am J Physiol 1994 ; 267: H1383-95.

20 Wang S, Morales MJ, Qu YJ, Bett GC, Strauss HC, Rasmusson RL. Kv1.4 channel block by quinidine: evidence for a drug induced allosteric effect. J Physiol 2003; 546: 387-401.

21 Madeja M, Leicher T, Friederich P, Punke MA, Haverkamp W, Musshoff $U$, et al. Molecular site of action of the antiarrhythmic drug propafenone at the voltage-operated potassium channel Kv2.1. Mol Pharmacol 2003; 63: 547-56.

22 Arias C, González T, Moreno I, Caballero R, Delpón E, Tamargo J, et al. Effects of propafenone and its main metabolite, 5-hydroxypropafenone, on hERG channels. Cardiovasc Res 2003; 57: 660-9.

23 Franqueza L, Valenzuela C, Delpón E, Longobardo M, Caballero R, Tamargo J. Effects of propafenone and 5-hydroxy-propafenone on hKv1.5 channels. Br J Pharmacol 1998; 125: 969-78.

24 Paul AA, Witchel HJ, Hancox JC. Inhibition of the current of heterologously expressed hERG potassium channels by flecainide and comparison with quinidine, propafenone and lignocaine. $\mathrm{Br} J$ Pharmacol 2002; 136: 717-29.

25 Gao Z, Sun H, Chiu SW, Lau CP, Li GR. Effects of diltiazem and nifedipine on transient outward and ultra rapid delayed rectifier potassium currents in human atrial myocytes. Br J Pharmacol 2005; 144: 595-604.

26 Duan D, Fermini B, Nattel S. Potassium channel blocking properties of propafenone in rabbit atrial myocytes. J Pharmacol Exp Ther 1993; 264: 1113-23.

27 Hoppe UC, Beuckelmann DJ. Modulation of the hyperpolarization activated inward current (If) by antiarrhythmic agents in isolated human atrial myocytes. Nauny Schmiedebergs Arch Pharmacol 1998; 358: 635-40.

28 Satoh H, Hashimoto K. Effect of propafenone on the membrane currents of rabbit sino-atrial node cells. Eur J Pharmacol 1984; 99 : 185-91.

29 Delpon E, Valenzuela C, Perez O, Casis O, Tamargo J. Propafenone preferentially blocks the rapidly activating component of delayed rectifier $\mathrm{K}^{+}$current in guinea pig ventricular myocytes. Voltageindependent and time-dependent block of the slowly activating component. Circ Res 1995; 76: 223-35.

30 Snyders J, Knoth KM, Roberds SL, Tamkun MM. Time-, voltage-, and state-dependent block by quinidine of a cloned human cardiac potassium channel. Mol Pharmacol 1992; 41: 322-30.

31 Slawsky MT, Castle NA. $\mathrm{K}^{+}$channel blocking actions of flecainide compared with those of propafenone and quinidine in adult rat ventricular myocytes. J Pharmacol Exp Ther 1994; 269: 66-74.

32 Wang S, Morales MJ, Liu S, Strauss HC, Rasmusson RL. Modulation of hERG affinity for E-4031 by $\left[\mathrm{K}^{+}\right]_{0}$ and C-type inactivation. FEBS Lett 1997; 417: 43-47.

33 Nerbonne JM, Nichols CG, Schwarz TL, Escande D. Genetic manipulation of cardiac $\mathrm{K}^{+}$channel function in mice: what have we learned, and where do we go from here? Circ Res 2001; 89: 94456.

34 Strauss HC, Morales MJ, Wang S, Brahmajothi MV, Campbell DL. Voltage-dependent $\mathrm{K}^{+}$channels. In: Sperelakis N, Kurachi Y, Terzic A, Cohen MV editors; Heart physiology and pathophysiology. San Diego (California): Academic Press; 2001. p 259-80. 